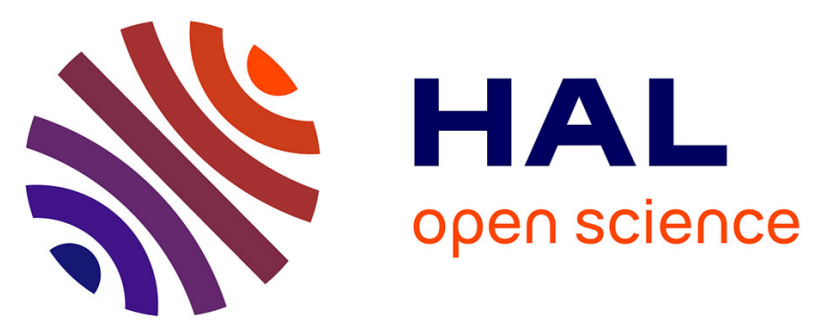

\title{
Bulky extramedullary hematopoiesis is not a rare complication of congenital dyserythropoietic anemia
}

Hermann Heimpel, Ulrich Dührsen, P. Hofbauer, V. Rigamonti-Wermlinger, Ernst-Dietrich Kreuser, Klaus Schwarz, Max Solenthaler, S. Pauls

\section{- To cite this version:}

Hermann Heimpel, Ulrich Dührsen, P. Hofbauer, V. Rigamonti-Wermlinger, Ernst-Dietrich Kreuser, et al. Bulky extramedullary hematopoiesis is not a rare complication of congenital dyserythropoietic anemia. Annals of Hematology, 2009, 88 (10), pp.937-941. 10.1007/s00277-009-0735-5 . hal00535048

\author{
HAL Id: hal-00535048 \\ https://hal.science/hal-00535048
}

Submitted on 11 Nov 2010

HAL is a multi-disciplinary open access archive for the deposit and dissemination of scientific research documents, whether they are published or not. The documents may come from teaching and research institutions in France or abroad, or from public or private research centers.
L'archive ouverte pluridisciplinaire HAL, est destinée au dépôt et à la diffusion de documents scientifiques de niveau recherche, publiés ou non, émanant des établissements d'enseignement et de recherche français ou étrangers, des laboratoires publics ou privés. 


\title{
Bulky extramedullary hematopoiesis is not a rare complication of congenital dyserythropoietic anemia
}

\author{
Hermann Heimpel • Ulrich Dührsen • P. Hofbauer • \\ V. Rigamonti-Wermlinger • Ernst-Dietrich Kreuser • \\ Klaus Schwarz • Max Solenthaler • S. Pauls
}

Received: 11 February 2009 / Accepted: 9 March 2009 /Published online: 31 March 2009

(C) Springer-Verlag 2009

\begin{abstract}
Bulky extramedullary hematopoiesis, usually detected in the thorax by imaging techniques, is a wellknown complication in many types of congenital anemias. Here, we describe 12 cases of congenital dyserythropoietic anemia with extramedullary hematopoiesis which was always located in the paravertebral space of the thoracic spine and in other paraspinal regions in a few cases. All bulks were originally detected in chest radiographs and confirmed by imaging techniques such as computed
\end{abstract}

\author{
H. Heimpel ( $\bowtie)$ \\ Medizinische Klinik III, Universitätsklinikum Ulm, \\ Ulm, Germany \\ e-mail: hermann.heimpel@uniklinik-ulm.de \\ U. Dührsen \\ Klinik für Hämatologie, Universität Essen, \\ Essen, Germany \\ P. Hofbauer \\ Fachpraxis für Lungenkrankheiten, \\ Weinheim, Germany \\ V. Rigamonti-Wermlinger $\cdot M$. Solenthaler \\ Abteilung für Hämatologie and Hämatologisches \\ Zentralaboratoratorium, Universitätsklinik und Universität Bern, \\ Bern, Switzerland \\ E.-D. Kreuser \\ Klinik für Onkologie, Krankenhaus der barmherzigen Brüder, \\ Regensburg, Germany \\ K. Schwarz \\ Institut für klinische Transfusionsmedizin und Immungenetik \\ und Institut für Transfusionsmedizin, Universitätsklinikum Ulm, \\ Ulm, Germany \\ S. Pauls \\ Klinik für Diagnostische und Interventionelle Radiologie, \\ Universitätsklinikum Ulm, \\ Ulm, Germany
}

tomography and/or magnetic resonance imaging. In some cases, thoracotomy was performed for suspected malignancy. Although the true prevalence is not known, paravertebral masses in patients with CDA of any type are not uncommon and should be the first differential diagnosis considered when masses adjacent to the spine are detected in this disorder.

Keywords Congenital dyserythropoietic anemia . Extramedullary hematopoiesis $\cdot$ Imaging techniques

\section{Introduction}

Bulky extramedullary hematopoiesis, usually detected in the thorax by imaging techniques, is a well-known complication in many types of congenital anemias. It has been reported in up to $15 \%$ of patients with thalassemia intermedia [1] and also in hereditary hemolytic anemias, such as sickle-cell-disease [2], hereditary spherocytosis [3, 4] or pyruvate kinase deficiency[5]. In the majority of cases it is detected accidentally on routine X-ray of the thorax [6]. Usually it is asymptomatic, but may present a problem of differential diagnosis and result in extensive diagnostic procedures, which may prompt thoracotomy if a neoplastic lesion is suspected.

Here, we report six cases of bulky extramedullary erythropoiesis in a cohort of patients with congenital dyserythropoietic anemias (CDAs) observed since 1971 and review six further cases published as case reports in the literature.

\section{Materials and methods}

All cases were extracted from the data bank of the German registry on CDAs. The registry collates all cases of CDA 
Table 1 CDA_UPN: code of the German Registry on CDAs

\begin{tabular}{|c|c|c|c|c|c|c|c|c|c|}
\hline CDA_UPN & Type & Sex & Country & Age & Method & site & Symptoms & $\mathrm{Sx}$ & Hemoglobin $\mathrm{g} / \mathrm{d} \mathrm{l}$ \\
\hline $026 / 01$ & I & $\mathrm{F}$ & $\mathrm{DE}$ & 32 & X-ray & Thorax right, paravertebral & No & No & 9.3 \\
\hline $398 / 01$ & I & $\mathrm{F}$ & $\mathrm{CH}$ & 56 & $\mathrm{X}$-ray, CT & Thorax bi, paravertebral & Yes & No & 11.6 \\
\hline $065 / 01$ & II & $\mathrm{F}$ & $\mathrm{DE}$ & 48 & X-ray, CT, SPECT & $\begin{array}{c}\text { Thorax bi paravertebral, } \\
\text { pleura bi presacral }\end{array}$ & Yes & No & 7.6 \\
\hline $116 / 01[13]$ & II & $\mathrm{F}$ & IL & 55 & X-ray & Thorax bi paravertebral & No & No & 10.7 \\
\hline $116 / 02[13]$ & II & $\mathrm{F}$ & IL & 51 & $\mathrm{X}$-ray, CT & Thorax bi, paravertebral & No & No & 13 \\
\hline $182 / 01[15]$ & II & $\mathrm{F}$ & $\mathrm{CZ}$ & 41 & $\mathrm{X}$ ray, MRI, CT & Thorax bi, LS paravertebral & No & No & 8.0 \\
\hline $245 / 01[16]$ & II & M & $\mathrm{BR}$ & 13 & $\mathrm{X}$-ray, CT & Paravertebral & No & No & 9.1 \\
\hline $252 / 01$ & II & M & $\mathrm{DE}$ & 42 & $\mathrm{CT}$ & Thorax bi paravertebral & No & No & 10 \\
\hline $405 / 01$ & II & $\mathrm{F}$ & $\mathrm{DE}$ & 56 & X-ray & Thorax ?paravertebral & No & Yes & 9.9 \\
\hline $322 / 01[17]$ & II & M & GB & 63 & CT & Thorax left, paravertebral & No & Yes & 11.5 \\
\hline 023/01 [18] & III & $\mathrm{F}$ & NL & 33 & X-ray, CT, SPECT & Thorax bi, paravertebral & Yes & No & 7.6 \\
\hline $203 / 01$ & var & M & $\mathrm{DE}$ & 39 & $\mathrm{X}$-ray, CT & Thorax bi, paravertebral & Yes & Yes & 7.4 \\
\hline
\end{tabular}

Age age (years) when extramedullary bulk was first detected, Country country of residence at time of diagnosis, $B i$, bilateral, $S x$ splenectomy

seen in the departments of pediatric and adult hematology of the university of Ulm, as well as cases treated by other institutions known to the registry by correspondence and subsequent regular follow-up ("Own cases"). Collection and analysis of data was approved by the ethical committee of the University of Ulm, Germany. For data privacy protection, all cases were coded using a unique patient's number (CDA-UPN), thereby preventing recurrence of individual data. Also, patients reported in the literature also received a CDA_UPN. Due to the interest on this very rare disorder, many cases were published more than once; utmost care was taken to exclude double notifications. Diagnosis including classification of the type of CDA followed the definition criteria published before [7] and by detection of mutations in the CDAN1 gene [8] in cases 026/ 01 and 398/01.

In four of our six patients, computed tomography (CT) and magnetic resonance imaging (MRI) were available as print outs or digital data. The CT scans were performed after contrast medium application (portalvenous phase, slice thickness of $5 \mathrm{~mm}$ ). In case $252 / 01$, only a chest CT was performed, in patient $065 / 01$, the CT scan included the chest as well as the upper abdomen.

In patient no. 203/01, MRI of the cervical spine, the thorax, and the whole abdomen was acquired with the following axial sequences: native T1-weighted (FLASH 2 D) and T2-weighted sequences (HASTE) as well as contrast-enhanced T1-weighted sequences (VIBE) with fat saturation.

In patient no. 065/01, MRI of the thorax was performed with the following sequences: T2-weighted turbo spin echo (TSE) sequence (native) and T1-weighted spin echo sequence native and after contrast medium application in transversal and coronal slices.

\section{Results}

Pertinent data of 12 cases from 11 families are shown in Table 1. Eight and two out of 12 cases are of the less uncommon types II and I, respectively. In case 203/01 with additional thrombocytopenia, a GATA1 mutation was detected. In all cases masses were originally detected by chest X-ray and confirmed by computed tomography or magnetic resonance imaging. In case 252/01, a contrastenhanced CT was performed for confirmation of pulmonary embolism after splenectomy at the age of 42 years (Fig. 1); however, when previous radiographs films where retro-

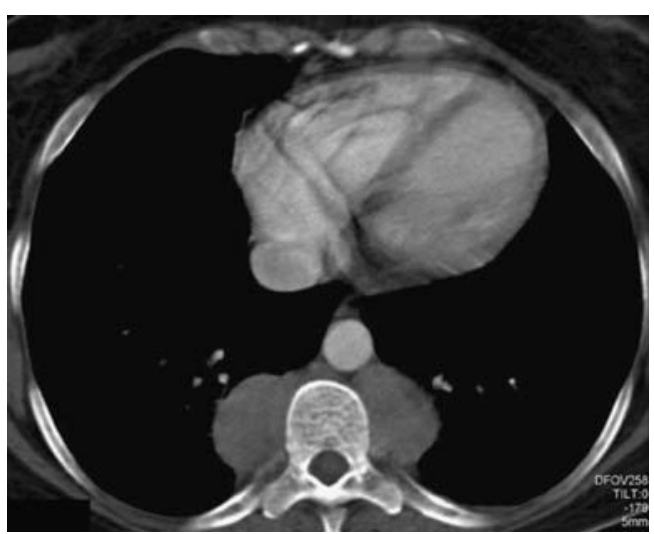

Fig. 1 CT-scan of a 42-year-old female with CDA II (UPN 252/01) 
spectively analyzed, the mass was already seen at the age of 35 years. Age at which the thoracic mass was first detected varied between 11 and 52 years.

In three cases, the lesions caused symptoms. In case 065/ 01, the large bulks (Fig. 2) probably contributed to the respiratory problems in addition to anemia and heart failure. The masses were removed by thoracotomy at the age of 48 years but had regrown, and at the age of 63 years they reached the same size as before. Bilateral pleural effusions with respiratory distress were reported in case $023 / 01$; the patient's condition improved after thoracocentesis and additional treatment with low-dose hydroxyurea and transfusions. In patient 398/01, the left-sided lesions caused neuropathic pain, which disappeared after local irradiation. In three cases, the detection of intrathoracic masses prompted thoracotomy before CT became available.

Histology and/or fine needle aspiration cytology was obtained in three cases The material showed mixed hematopoiesis, with preponderance of erythroblasts show-
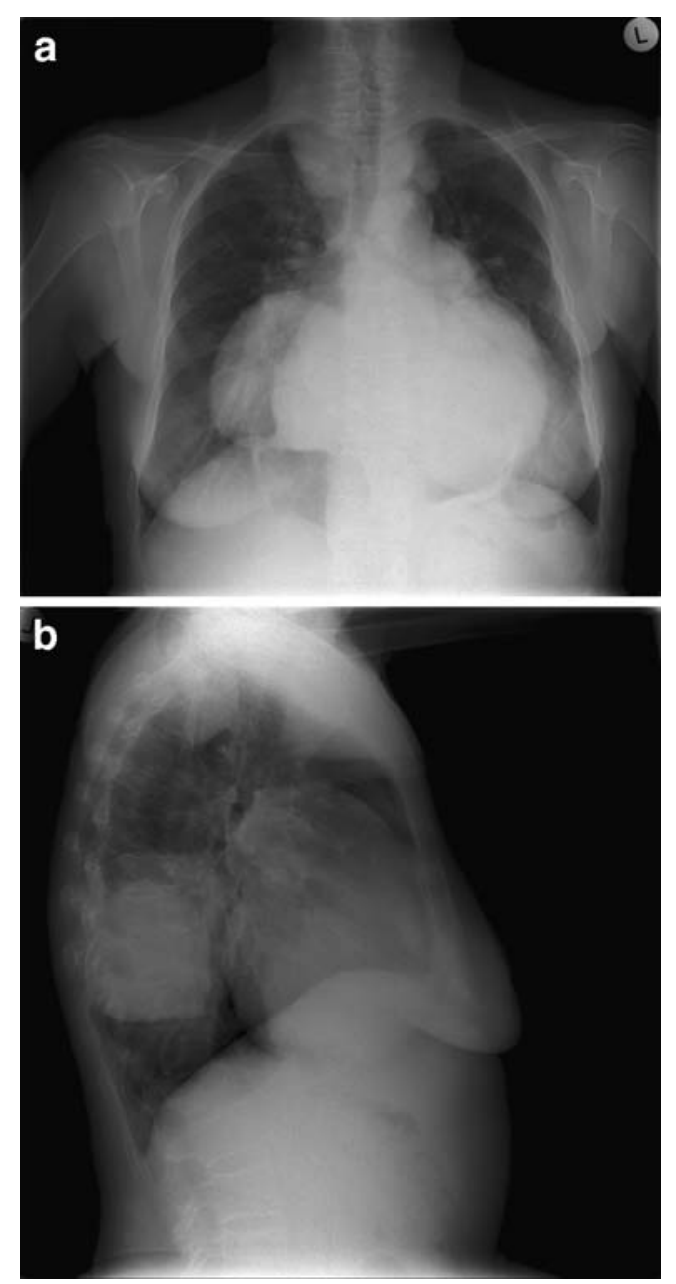

Fig. 2 X-ray of a 63-year-old female with CDA II (UPN 065/01) ing abnormalities on morphology as seen in the bone marrow. In case 026/01, a touch imprint made from the tumor bulk showed identical alterations as seen in the bone marrow (Fig. 3).

On computed tomography and magnetic resonance imaging, the paravertebral masses were located paraspinal and bilateral. On CT, the masses were isointense to the muscle tissue, relatively homogeneous and show no significant contrast enhancement. On MRI, the masses showed a homogenous contrast enhancement. No direct connection to the bone marrow of the vertebrae body could be found. The bone marrow in the tumor's area showed no alteration in the contrast enhancement compared to the bone marrow in other spine regions. On T2-weighted images, the larger masses showed a hyperintense signal in the central area of the mass (Fig. 4) as a sign of edema.

\section{Discussion}

Extramedullary hematopoiesis beyond liver and spleen has been observed in both neoplastic and benign blood disorders. Within the latter, masses of extramedullary hematopoiesis may present in a variety of hereditary anemias with expansion of the erythroid bone marrow, such as thalassemia, sickle cell disease, and hemolytic anemias, particularly in hereditary spherocytosis (HS) [6, 9]. No figures on the prevalence within the different types of hemolytic anemia are available; the fact that most case reports describe bulky extramedullary hematopoiesis in HS may be just due to the higher prevalence of HS as compared with other types of hereditary hemolytic anemias.

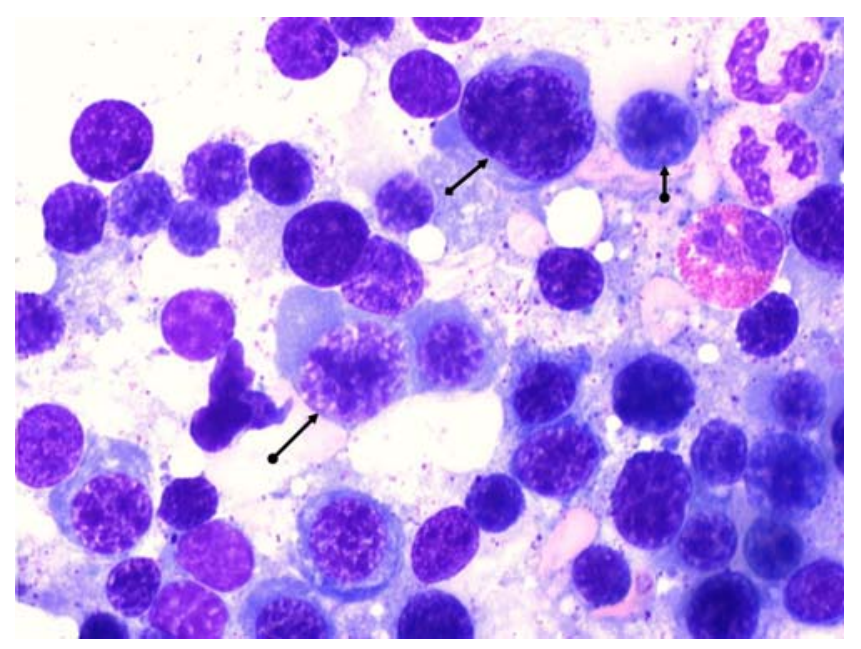

Fig. 3 Imprint of the bulk removed by thoracotomy 32-year-old female with CDA I (UPN 026/01). May-Grünwald panoptic stain. large polyploid erythroblast $\longleftrightarrow$ erythroblasts with abnormal chromatin structure 
Fig. 4 MRI sequences of the thorax from patient no. $065 / 01$. Left Smooth delined paraspinal masses with hyperintense signal in $\mathrm{T} 2 \mathrm{w}$ sequence (axial slice) into the right paraspinal mass which corresponds to an edema. Right Contrast-enhanced T1 w sequence (coronar) with homogenous contrast enhancement of the masses
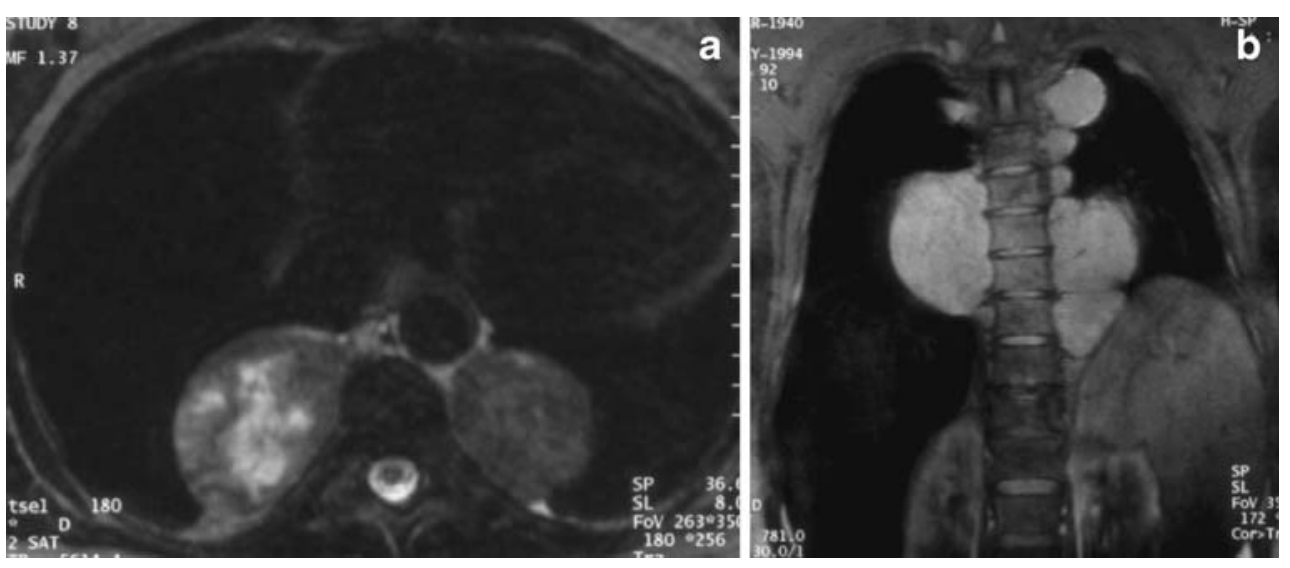

Altogether the occurrence in 12 cases with CDAs is known (Table 1). In a 32-year-old female with CDA I (026/ 01 ), a right-sided large paravertebral tumor was removed by thoracotomy. The same was true in a female with CDA II $(065 / 01)$. Here, a thoracic mass was removed at the age of 48 years. Eighteen years later the bulk had regrown, as shown in Fig. 2. Considering the rareness of the CDAs, with an estimated prevalence of one in 0.5 to one million families (publication pendent), the number of observations of bulky extramedullary disease seems to be rather high. Again, we cannot provide sound data on the prevalence. Data to be obtained in cases of the German registry does not include routine CT scans of the thorax. As shown in case $252 / 01$, chest X-ray alone may fail to detect paravertebral bulks and such masses may have remained undetected in other cases.

In CDAs, bulky extramedullary hematopoesis is usually confined to the paravertebral space of the thoracic spine, extending to the pleural space and compressing the lung in single cases. In one case, foci extended to the upper lumbar spine and in another case a presacral mass was detected. This observation favors the hypothesis that this pattern is rather due to the extrusion of the hyperplastic hemopoietic (erythroid) marrow rather than deposition of circulating hemopoietic stem cells, as assumed to occur in non-bulky hemopoietic foci observed in liver and spleen. However, the alternative hypothesis that the bulks observed develop from heterotopic hemopoietic cells is not excluded and is supported by autopsy findings failing any continuity between the ribs and the paravertebral masses [10]. We did not observe compression of the spinal cord by a paravertebral mass, as described in thalassemia [11, 12]. However, this may also occur in other forms of ineffective erythropoiesis and therefore this possibility should be included in the differential diagnosis of neurological deficits of the lower limbs in patients with CDA. Extramedullary hematopoiesis is often considered as a compensatory mechanism in certain benign (congenital hemolysis) as well as malignant (myeloid metaplasia, myelopthisis) forms of chronic anemia. However, at least for the case of CDA, this is not a satisfying explanation. In our own cases, hemoglobin concentration at the time the bulk first was detected varied between 7.6 and $11.6 \mathrm{~g} / \mathrm{dl}$. In a report on three siblings of Moroccan origin with CDA type II, thoracic masses were detected in two of them, including one female who even had a normal hemoglobin [13]. A lifelong erythroid hyperplasia is the most plausible explanation.

On computed tomography, the paravertebral masses are typically bilateral, isointense to the muscle tissue, homogeneous, and show no significant contrast enhancement [2]. During therapy, the size as well as the density of these paravertebral tumors may change. Differentiating neurogenic tumors such as neurofibromatosis type I or lymphoma has to be taken into consideration based on chest X-ray and also CT imaging alone. Additionally, imaging methods can be necessary to differentiate these masses. Single photon emission tomography (SPECT) after application of 99-TClabeled antineutrophilic antibodies [14] specifically detects hematopoietic tissue. The combined SPECT/CT technique provides functional and morphologic information about the tumors and yields a high accuracy in diagnosis of an extramedullary hematopoiesis.

In conclusion, physicians who care for patients with CDA should be aware of the possibility that any masses detected in the thorax or adjacent to the spine could be extrusions of the hyperplastic marrow. No surgical interventions should be done unless there is evidence of neoplastic features of the lesion. Diligent analysis of the tissue structure, CT-directed needle aspirates and CT scans to detect hemopoietic bulk at other sites should be performed before the decision of a surgical removal is made in order to avoid iatrogenic damage in a chronic, nonmalignant disease. 


\section{References}

1. Taher A, Isma'eel H, Cappellini MD (2006) Thalassemia intermedia: revisited. Blood Cells Mol Dis 37:12-20. doi:10.1016/j.bcmd.2006.04.005

2. Gumbs RV, Higginbotham-Ford EA, Teal JS, Kletter GG, Castro O (1987) Thoracic extramedullary hematopoiesis in sickle-cell disease. AJR Am J Roentgenol 149:889-893

3. Bastion Y, Coiffier B, Felman P, Assouline D, Tigaud J-D, Espinouse D, Bryon P-A (1990) Massive mediastinal extramedullary hematopoiesis in hereditary spherocytosis: a case report. Am J Hematol 35:263-265. doi:10.1002/ajh.2830350408

4. Pulsoni A et al (1992) Mediastinal extramedullary hematopoiesis as first manifestation of hereditary spherocytosis. Ann Hematol 65:196-198. doi:10.1007/BF01703115

5. Plensa E, Tapia G, Junca J, Perez R, Castella E, Marti S (2005) Paravertebral extramedullary hematopoiesis due to pyruvate kinase deficiency. Haematologica 90 Suppl:ECR32.:ECR32

6. Bowling MR, Cauthen CG, Perry CD, Patel NP, Bergman S, Link KM, Sane AC, Conforti JF (2008) Pulmonary extramedullary hematopoiesis. J Thorac Imaging 23:138-141. doi:10.1097/ RTI.0b013e31815b89aa

7. Heimpel H, Anselstetter V, Chrobak L, Denecke J, Einsiedler B, Gallmeier K, Griesshammer A, Marquardt T, Janka-Schaub G, Kron M, Kohne E (2003) Congenital dyserythropoietic anemia type II: epidemiology, clinical appearance, and prognosis based on long-term observation. Blood 102:4576-4581. doi:10.1182/blood2003-02-0613

8. Heimpel H, Schwarz K, Ebnöther M, Goede J, Heydrich D, Kamp T, Plaumann L, Rath B, Roessler J, Schildknecht O, Schmid M, Wuillemin W, Einsiedler B, Leichtle R, Tamary H, Kohne E (2006) Congenital dyserythropoietic anemia type I (CDA I): molecular genetics, clinical appearance and prognosis based on long-term observation. Blood 107:334-340. doi:10.1182/blood-2005-01-0421
9. Koch CA, Li CY, Mesa RA, Tefferi A (2003) Nonhepatosplenic extramedullary hematopoiesis: associated diseases, pathology, clinical course, and treatment. Mayo Clin Proc 78:1223-1233. doi: $10.4065 / 78.10 .1223$

10. Verani R, Olson J, Moake JL (1980) Intrathoracic extramedullary hematopoiesis: report of a case in a patient with sickle-cell disease-beta-thalassemia. Am J Clin Pathol 73:133-137

11. Hassoun H, Lawn-Tsao L, Langevin ER Jr, Lathi ES, Palek J (1991) Spinal cord compression secondary to extramedullary hematopoiesis: a noninvasive management based on MRI. Am J Hematol 37:201-203. doi:10.1002/ajh.2830370314

12. Saghafi M, Shirdel A, Lari SM (2005) Extramedullary hematopoiesis with spinal cord compression in beta-thalassemia intermedia. Eur J Intern Med 16:596-597. doi:10.1016/j.ejim.2005.04.010

13. Lugassy G, Michaeli J, Harats N, Libson E, Rachmilewitz EA (1986) Paravertebral extramedullary hematopoiesis associated with improvement of anemia in congenital dyserythropoietic anemia type II. Am J Hematol 22:295-300. doi:10.1002/ajh.2830220310

14. Denzlinger C, Humann M, Steiner W, Bader J, Greither L, Gunther W, Reisbach G, Munker R, Baumgart R, Leeping M et al (1995) 54jährige Patientin mit Anämie, Ikterus, Hepatosplenomegalie und paravertebralen Raumforderungen. Internist (Berl) 36:726-729

15. Herman M, Rocek V, Rehulka M, Indrak K, Gumulec J, Dusek J (1995) Bilateral asymptomatic masses in posterior mediastinum. Intrathoracic extramedullary hematopoiesis. Radiologe 35:297-299

16. Hines GL (1993) Paravertebral extramedullary hematopoiesis (as a posterior mediastinal tumor) associated with congenital dyserythropoietic anemia. J Thorac Cardiovasc Surg 106:760-761

17. Imran A, Mawhinney R, Swirsky D, Hall C (2008) Paravertebral extramedullary haemopoiesis occurring in a case of congenital dyserythropoietic anaemia type II. Br J Haematol 140:1

18. Krouwels FH, Bresser P, von dem Borne EKG (1999) Extramedullary hematopoisis: breath-taking and hair-raising. N Engl J Med 341:1702-1703. doi:10.1056/NEJM199911253412219 